Benefits The system has allowed improved communication between members of the team. The template has served as a management checklist ensuring that important components of COPD care are not forgotten. The system has been used to identify patients with very severe disease for discussion at a severe disease MDT and been associated with a $5 \%$ reduction in outpatient attendances.

\section{P283 RELATIONSHIP BETWEEN THE RANKING OF COPD OUTCOME MEASURES (RE-ADMISSIONS AND EMERGENCY BED DAYS) AND RESPIRATORY SERVICE PROVISION ACROSS THE 13 PCTS IN THE EAST OF ENGLAND (EOE)}

doi:10.1136/thoraxjnl-2012-202678.375

'AG Davison, 'L Jongepier, 'L Paddison, ${ }^{2} \mathrm{~K}$ Smith, ${ }^{2} \mathrm{JR}$ Flowers. ${ }^{1} \mathrm{NHS}$ Midlands and East, Cambridge; ${ }^{2} E n g l a n d$, Quality Intelligence East, Eastern Public Health Observatory, Cambridge, England

The White Paper "Equity and Excellence. Liberating the NHS" stated that the health service must be focused on two key parameters i) outcomes and ii) the quality standards that deliver them. As there is little data examining their relationship in COPD we have examined this in the EoE.

Methods Two COPD outcome measures from INHALE (www. inhale@nhs.uk), emergency bed days for COPD admissions per 1000 PCT population for 2010-11, and \% emergency re-admissions within 28 days for 2010-11, have been ranked from 1-13 for all PCTs in the EoE A questionnaire has been developed by the EoE. Respiratory Team to assess respiratory service provision. This was completed by all the respiratory networks in the 13 PCTs in April 2012. The presence of 4 services in the PCTs ranked in the top 6 have been compared to their presence in the bottom 7 PCTs. 11 PCTs have one local hospital.

Results All COPD admissions were under the care of the respiratory team in $50 \%$ of hospital ranked in the top 6 , compared with $43 \%$ of those ranked in the bottom 7 . A discharge bundle was in place in $33 \%$ of hospitals in the top 6, compared with $57 \%$ in the bottom 7 . An early discharge scheme was in place in $66 \%$ of those in the top 6 , compared with $57 \%$ in the bottom 7 . An integrated care pathway existed in 33\% of those in the top 6, compared with $100 \%$ in the bottom 7 .

Conclusion We had expected to find a relationship but these results suggest that the existence of various services cannot be used as a surrogate for outcome measures. It would be expected that the existence of these services would improve the outcomes. The services were present in April 2012 but may have been introduced after or during 2010-11 when outcomes were measured. Auditing is also necessary to show that services are effective. Outcomes may also have improved in some areas after the introduction of services but those PCTs may still be ranked below others. In future trend analysis will be more useful than simple ranking.

\section{P284 QUALITY IMPROVEMENTS AND COST SAVINGS ASSOCIATED WITH THE INTEGRATION OF COPD CARE IN COVENTRY}

doi:10.1136/thoraxjnl-2012-202678.376

${ }^{1} \mathrm{CM}$ Gelder, ${ }^{2} \mathrm{M}$ Horn, ${ }^{2} \mathrm{~J}$ Horn, ${ }^{3} \mathrm{G}$ Washington. 'University Hospitals Coventry \& Warwickshire NHS Trust, Coventry, UK; ${ }^{2}$ Godiva Clinical Commissioning Group, Coventry, UK; ${ }^{3}$ Coventry Primary Care Trust, Coventry, UK

Introduction Coventry had high admissions rates for COPD, and poor co-ordination between primary and secondary care. There was generally low interest in COPD and poor attendance at educational meetings. An audit revealed that $74 \%$ of individuals with COPD admitted to hospital made contact with their practise in the month before admissions and $58 \%$ had received 3 or more courses of antibiotics in the year prior to admission, indicating the potential to improve care quality and reduce costs.

Methods We reviewed current provision against NICE standards and the emerging National COPD Strategy, identified gaps and agreed priorities. In parallel a patient and carer consultation was undertaken using focus groups, interviews and questionnaires. This information was used to formulate a model that integrated primary and secondary care and shared clinical pathways. Key was the establishment of a consultant led community based COPD team.

To allow individual practises to benchmark themselves against NICE standards and then support them to develop their own improvement plans, a COPD management tool (POINTS) was introduced into most practises.

Financial incentives (OP 8 and $\mathrm{OP} 11$ ) were used to drive key elements, in particular improved recording of exacerbations, the use of rescue packs and self-management plans. Education for Primary Care Nurses was made "user-friendly" and delivered as monthly "bite size' education sessions, with GP reimbursement for nurse time.

Results There has been a high level of support and engagement from primary and secondary care. COPD is now the top local LTC priority. During the first year admissions and re-admissions have reduced by approximately $15 \%$. More than $90 \%$ of COPD outpatient activity is now in the community (including post discharge follow up).

Patient surveys have shown very high levels of satisfaction.

The project has been cost neutral in its first year (including savings from Oxygen Register cleansing but excluding savings from moving outpatient care to the community team) and the CCGs project savings of approximately $£ 300,000$ and $£ 600,000$ at 24 and 36 months.

Discussion This demonstrates that service redesign can deliver rapid improvements in the quality of care with significant cost savings potential.

\section{P285 BEYOND CARE BUNDLES: THE DEVELOPMENT OF A STRUCTURED ADMISSION MODEL}

doi:10.1136/thoraxjnl-2012-202678.377

C Thompson, A Robinson, P Duncan. NHS Improvement, Leicester, UK

Hospital admission for acute respiratory disease accounts for $40 \%$ of the cost of managing respiratory disease in the UK. Data from national and European respiratory audits suggest the quality of care received is highly variable, and in the UK only $50 \%$ of people admitted for exacerbation of COPD will be managed by respiratory physicians. Admission to hospital is a significant event for someone with respiratory disease and represents an opportunity for the patient to receive a comprehensive and high quality respiratory review and interventions. Through project work with five project sites a structured admission model was developed and implemented through service improvement and process redesign. The components of the model include:

- Appropriate and timely (within 3 hours of admission) access to non-invasive ventilation (NIV)

- Access to respiratory specialist within 24 hours

- Proactive identification and management of high impact service users

- Ensuring every patient receives the key aspects of care during their admission (e.g. smoking cessation, inhaler technique cheque, self management plan) 